\title{
The Rise of the Nursing Academic Leader: Pathways to Deanship
}

\author{
Lesley Wilkes ${ }^{1, *}, J_{0 h n}$ Daly $^{2}$, Wendy Cross ${ }^{3}$, Debra Jackson $^{4}$ \\ ${ }^{1}$ Centre for Nursing Research and Practice Development- University of Western Sydney, Nepean Blue Mountains Local Health District, \\ Nepean Hospital, Australia \\ ${ }^{2}$ Faculty of Health, University of Technology, Australia \\ ${ }^{3}$ School of Nursing \& Midwifery, Faculty of Medicine, Nursing and Health Sciences, Monash University, Australia \\ ${ }^{4}$ Faculty of Health and Life Sciences, Oxford Brookes University, UK
}

Copyright (C) 2015 Horizon Research Publishing All rights reserved.

\begin{abstract}
Purpose: This paper aims to describe the education and career pathways of a group of nursing deans in the late 20th and 21 st centuries. The study explores nursing deans to understand the career development process and to develop recommendations for succession planning. Methods: A qualitative interview captured the oral histories of 30 nursing deans from Canada, United Kingdom and Australia in 2011 and 2012. Career and educational pathways were mapped, tabulated and exemplars used to emphasise key education and career decisions. Results: Findings show that there are four distinctive pathways to becoming a nursing dean and these are: 1 . Same university pathway: Clinical work to teaching and thence the promotion and leadership in education route and pursuit of deanship in the same institution; 2. Different university pathway: Clinical work to teaching thence the promotion and leadership in education route and pursuit of deanship at a different institution in the same country; 3 . Different country pathway: Clinical work to teaching thence the promotion and leadership in education route and pursuit of deanship at a different institution in different country; and 4. Health pathway: Clinical work to clinical management to dean route. Conclusion: The career and educational pathways of the 30 deans described will inform aspiring deans and highlight the importance of doctoral qualifications, management experience and leadership qualifications. Importantly, these aspirants need to determine the particular institutional culture into which they aspire to commit to becoming a dean of nursing.
\end{abstract}

Keywords Academic Dean, Career Pathway, Qualitative Research

\section{Introduction}

Much of the research on deanship is conducted in the United States of America (USA) where there are predictions of a looming decline in candidates for deanships in the next ten years. $[1,2]$ This shortage is also forecast for academic nursing deans. $[3,4]$ The reasons for this have been attributed to burnout, retirement of senior education administrators and the reluctance of faculty to make the transition to senior administrative positions.[1] Similar predictions have been made for nursing deanship candidates and nurse educators in Europe and the USA.[5] For the purposes of this paper, we define deanship as a senior member of the academic staff heading a nursing faculty/school and responsible for faculty personnel and nursing programs within a university.

There is general agreement that senior nursing academic administrators are needed to meet the demands of the 21 st century and to achieve sustainable leadership capacity. However, there is an imbalance in the demand and supply of people with suitable skills.[3] Green and Ridenour [6] have emphasised that shaping a career in academic administration in nursing requires careful consideration by prospective candidates because of the trajectory to the role of dean, and the extent of the challenges associated with the role. However, little has been documented regarding the journey of nurses to academic deanship. This paper reports the findings of a qualitative study of the career pathways of nursing deans in three countries.

Many routes lead to deanship, [6] and traditionally, Deans have been considered to be teachers and scholars first and administrators second.[7] Deans may have prior experience in leadership roles in education at a university but usually have little formal training.[8] Indeed, the need for formal training may not be essential, as deans themselves have reported that the most valuable preparation for the role is past administrative experience.[9] However, with major changes in universities' operating environments predicted, with flatter structures, changing funding models, budgetary constraints and demands for entrepreneurial competence,[7] modifications to career pathways for future deans may become essential.

Various pathways to the deanship have been described in 
the literature.[10] The first, professional ascendency, entails moving from full professor to associate dean/departmental chair to dean; the second, a trained administrator moving from a line position of associate dean to dean; the third, the managerial outside transfer where the dean comes from another organisation and finally, the political appointment where knowing the right people and being in the right place is a route to the deanship. Green and Ridenour [6] suggest that many nurses follow the professional route from expert clinician to expert faculty, either moving through the ranks of academia or being thrust into senior leadership positions.

Another view of the conduit to deanship is presented by Bright and Richards [12]. These authors suggest three patterns: The faculty citizen dean, the corporate dean and the accidental tourist dean. The faculty deans see themselves as "doing the right thing" and have usually travelled the scholar route in the same institution. The corporate dean is one whose emphasis is on academic work, focusing on policies and resources, and usually comes from another smaller institution. The accidental tourist dean is the most common [11] and is where the dean starts as a member of faculty, progresses through departmental administration or governance roles. Traditionally as Wolverton et al [8] report, universities usually promote senior faculty to the deanship. In a study of community college leadership in USA over 20 years Amery et al [13] suggest that the emphasis on promoting through the ranks to the deanship is changing but this may not be true in universities. There has been little further work in this area since the early 2000's, however, much has changed since that time particularly the nature of increased international movement at the dean level, and also increasing concern about a crisis in the nursing academic workforce.[13]

The data for this paper are drawn from a larger international study examining the experiences of nursing deans. The study explored personal stories of becoming a nursing dean, the impact of the role on the participants' professional and personal lives and the leadership characteristics they considered essential to be successful in the dean role. We have published a paper on participant dean's perceptions of essential attributes for nursing deanship [14]. In this current paper, we focus on participants career pathways. This was seen as significant as no previous literature has focused on this aspect of nursing of the lives of nursing deans. As less nurse academics are striving to become deans it was thought that describing career pathways would provide advice and council in succession planning for both managers and prospective deans.

\section{Methods}

\section{Research design}

Personal oral histories (testimonies) were used to collect data for this part of the larger qualitative study. Oral testimonies are useful in that they can provide a view of history built around people. [15] Kirby [17] suggests that the process of interviews and personal biographies of historical and social events provides an understanding of past events that can be understood by others. Collective oral testimonies have the capacity to provide insight into understanding the cultural and behaviour of specific groups.[17] In this current study, the behaviours of interest were the participants' pathways to deanship in nursing.

\section{Participants and recruitment}

Participants were deans of nursing; that is, they were senior faculty with responsibility for staff, students and programs in nursing. Inclusion criteria required the participant to have held or currently hold such a position for at least one year, at any time from 1980-March 2012. Participants were recruited through the team's contacts and public web sites at universities in Canada, England and Australia. Initially, the Deans were approached by email to minimise any perception of coercion. If the Deans wished to be part of the project, they then had the autonomy to make contact with the team for further information before making the decision to participate. If a Dean did not respond to the initial contact, no further contact was made. All participation was voluntary.

\section{Data Collection}

Once a signed consent form was returned, a convenient time to be interviewed in person or by telephone was arranged. The oral testimonies were collected through conversational-style interviewing in which the participants were asked to trace their careers and education since starting nursing, commencing with an idea of why they became a nurse. Prompts were given throughout the conversation to gain more insight or clarification but no prescribed questions were used. All conversations were audio-taped. Data were collected by a senior nurse who herself met the inclusion criteria for the study, in that she had previously held a Dean of nursing position for a number of years.

\section{Data analysis}

The texts from the conversations were transcribed and integrated and the career and educational pathway for each participating Dean was mapped and tabulated. From this, patterns in the pathways were determined with similarities and differences identified so as to determine collective meaning. Exemplars are used in the results to emphasise career decisions and interruptions. To determine reasons why the participants took up nursing, narratives from the conversations were thematically analysed, similarities and differences compared and contrasted with major themes determined. To maintain rigour, maps, patterns in the data, themes and exemplars were audited by all members of the team. To allow ease of reading exemplars from the deans interviews are identified according to their career pathway; SUP indicates Same University Pathway (SUP 1-18), Different University (DUP 1-6), Health to Dean Pathway (HDP 1-2), Different Country Pathway (DCP 1-4) 
Ethical considerations

The proposal for this project was approved by the relevant Human Research Ethic Committees.

\section{Findings}

Conversational-style interviews were held with 30 deans of nursing. The final sample consisted of three deans from Canada, seven from England and 20 from Australia. Their experience as deans ranged from 1 to 22 years (mean $=8.4$, $\mathrm{SD}=5.98)$ with their age range being 45 to 75 years $($ mean $=$ $57, \mathrm{SD}=6.8$ ), with a third being between 56 and 60 years of age at time of interview. Seventy per cent $(n=21)$ were women. The most common first qualification in nursing was a hospital certificate in either general or mental health $(\mathrm{n}=$ $23,77 \%$ ). This was anticipated considering the age of the sample and that most of the deans came from

England and Australia ( $\mathrm{n}=27)$ where most often there was no diploma or degrees in nursing when they commenced their careers. The majority had held a single deanship $(n=18$, $60 \%$ ). The deans' career pathways to the deanship and education will be presented in detail.

\section{Education of the deans}

Table 1 summarizes the pursuit of education by the deans during their careers. There were no clear patterns in the data with many of the participants completing undergraduate and post graduate studies in both nursing and either education or management. In many cases they appear to accumulate a plethora of degrees as they progressed through their career path. Only two followed the common pathway of deans in many other disciplines from undergraduate education to $\mathrm{PhD}$. As $\mathrm{DCP} 2$ stated: I did my first degree in Manchester, one of the few places doing degrees in nursing and because of the unusualness of having a degree [as a nurse] I jumped into my PhD.

The drive to achieve qualifications for these deans was evident in many of their journeys with some pursuing both undergraduate and post graduate degrees at various levels. Most commonly, bachelor degrees were obtained through part-time study early in their career during clinical work or while a nurse educator or a nurse manager in a hospital. Not atypical of other participants' needs for higher degrees, one dean (SUP15) stated she completed her Bachelor in Nursing 16 years after her initial hospital based diploma.

I then started a Masters of Arts as there was no Masters in Nursing. It was in secondary education while I continued teaching in nursing, then I did a second Masters in Nursing. I did two Masters in five years and was out working and teaching and then I got a job at university and I needed a PhD (SUP15).

Again, Sue commenced her career with a diploma and some years later went back to school to do her Bachelor of Nursing and supplemented this with two Master degrees one in Social Work and one in Nursing before completing a Doctorate in Education. As she stated:
I felt the Masters of Social Work augmented what I knew in my nursing specialisation in mental health but after that I worked in public health nursing and I found an overlap between community nursing, mental health, public health and social work (DCP4).

Some participants pursued bachelor degrees in other areas. For example, SUP8 and DUP1 completed Bachelor of Psychology degrees while SUP4, SUP7, SUP12 completed Bachelor of Arts degrees while doing full-time clinical work. SUP18 completed her Bachelor of Arts with full-time study while doing part-time work within the clinical area.

Nursing clinical specialty qualifications were common with most completed at hospital certificate level in England and Australia (11\%). Education qualifications at Associate Diploma, Diploma and Masters levels were common when the participants were working as nurse educators in hospital programs. Some completed Masters degrees in education when lecturers $(4 \%)$ or concurrently with clinical work (4\%). One participant, SUP1, completed a Masters of Nursing with a clinical focus while in an educational leadership role at a university. Only three participants, SUP2, SUP5 and HDP2 completed formal post graduate education in management or nursing administration.

Three participants completed full-time Master of Nursing degrees at a single university in the 1980s with a noted nursing professor. All three of these participants independently expressed gratitude for the role of this single professor in their careers. Two of these degrees were completed while the participants did clinical work and the other after working as a nurse educator in a hospital and returning to work in a leader role in education in a tertiary program for nurses. Interestingly, two of these deans (SUP10 and SUP16) did not complete further study to a $\mathrm{PhD}$ although at the time of this study, one was enrolled in doctoral studies.

Doctoral education was most commonly pursued in part-time mode with $23(76.6 \%)$ completed when the deans were working as lecturers or in an educational leadership role. The two deans, who pursued the health pathway to deanship, completed their PhDs during the senior health management stage of their career. Two deans completed their $\mathrm{PhD}$ degrees full-time. HDP2 did this by interrupting his career as a hospital manager, and SUP3 by interrupting her career as a lecturer. SUP3 mixed both academia and clinical work during her pursuit of education and as she reflected:

I did my Masters part-time while in an academic position and then I went off and did my PhD full-time and followed this with a clinical community job in another country... it was very interesting helping other women to aspire to become educated. It was an amazing experience.

Pathways to the deanship

Prior to starting nursing, seven deans had other employment. One (SUP1) in clerical work, three as 
assistants in nursing (SUP2, SUP12 and DUP4), two deans were first aid officers (SUP16 and HDP2), and one dean did a number of untrained jobs (DUP5).

As indicated in Table 2, four distinct pathways to the deanship were evident from the data analysis (in brackets in Table 2 after Dean indicates decade of first appointment to deanship):

1. Same university pathway (SUP): Clinical work to teaching and thence the promotion and leadership in education route and pursuit of deanship in the same institution.

2. Different university pathway (DUP): Clinical work to teaching thence the promotion and leadership in education route and pursuit of deanship at a different institution in the same country.

3. Different country pathway (DCP): Clinical work to teaching thence the promotion and leadership in education route and pursuit of deanship at a different institution in a different country.

4. Health to Dean pathway (HDP): Clinical work to clinical management to dean route.

Same University Pathway

The most common pathway to deanship $(\mathrm{n}=18)$ across the decades was for the participants to work their way up the promotion ladder at one university and become dean either initially as associate dean in the case of SUP16 and DCP4; or as more usual from a senior educational leadership position in the faculty or school. As SUP14 stated: I started here... as an assistant professor and I just progressed through the ranks so now I am a full professor and dean. Many felt this pathway gave the background to pursue their dean role in a better fashion than if they were new appointees to the university. SUP15 reflected:

I was an internal appointment. When we became a faculty we had external appointments and then I was Associate Dean and when they did an external search this time I put my name in. I didn't know if I would be appointed but the culture that was here and where the faculty was at and they wanted to go with me as an internal Dean.

Contrary to the relative ease of being appointed internally as expressed by SUP9, another participant found some challenges in becoming dean at her former university. She had left and returned as Dean after some number of years away: When I came back... it was fascinating... the patterns were the same, the people interaction was very similar... it was awfully difficult because you have to develop a different relationship ... with a different mode (SUP14).

Others, like SUP4, felt they were pushed into the Dean position as there was no one else who wanted the position: $I$ was in senior lecturer position and they asked me to be head of school and then dean when we amalgamated to be a university... then when I changed universities I thought I am never doing administration again and after a year I was told I had to head nursing as there were no other professors. I did it for five years; recruited five professors and am now back to my research although they found that none of the other professors wanted to do the dean job (SUP4).

A number of the participants had worked in hospital-based nursing programs and moved to university programs when this became the norm for nursing. In Australia, during the 1980s, SUP9 had worked as a lecturer in a non-nursing discipline at a university then moved to a leadership position in an advanced college of education prior to becoming a Dean at that institution when it became a university.

I had no career plan, I don't think anyone of my generation did really; you weren't driven by career goals. There were a few jobs and I had to decide to work in the non-nursing or nursing discipline. This pushed my career into academic nursing... I had more passion about it. I went to ... [an Advanced College of Education\}... and when the decision to move nursing from hospitals I was one of the senior people who had experience in nursing education ... we travelled all over the country helping set up curricula and resources etc. (SUP9)

All the deans had worked for more than five years in the clinical arena with many continuing part-time clinical work while being a lecturer at the university. One dean, SUP1 had held leadership positions in health and education prior to her deanship.

SUP6 had a different pathway to her deanship. While she worked as a lecturer after hospital management, she had moved into leadership positions at the university. She moved to another university in the same city to take up a research only position in nursing. However, the head of school negotiated to make me deputy head and that started a life time of running more than one job. I did that for five years then went to another position connected to same university and came back as head of school while maintaining a professor role within the hospital (SUP6).

In the mid-2000s, one participant had previously lectured and held a leadership role in nursing education but had more recently been working in another health discipline as a lecturer and researcher when the university wanted to start running nursing programs and initiate a nursing school: $I$ sort of got a tap on the shoulder to help, start the school and write the initial program and get things up and running (SUP18). From there, SUP18 was appointed as head of school.

Eleven of these deans went on to other dean posts at other universities either in their own country or abroad. Dean 4 had another four appointments before retiring from her last deanship and these included one posting to a university abroad.

\section{Different University Pathway}

During the 1990s and 2000s, six participants moved to different universities in the same country to take up dean positions. Of these, three had started their teaching career as nurse educators in hospital programs. The others had moved from clinical work to lecturer positions.

DUP1 had moved countries to take up visiting scholar 
positions and leadership in education positions in Australia. During his leadership position, DUP1: learnt a lot about the Australian system and how things in higher education worked and this helped me when I got a job as Dean at another university. Unlike most of the deans DUP1 had had the opportunity to work as a post-doctoral fellow and in hospital management. Another participant, DUP3, had extensive clinical experience and overseas teaching experience before moving back to Australia and commencing: a Dean position at ...[another university]... I wasn't a professor when I got the role. I completed the promotion process and I got it (professorial status).

\section{Different Country Pathway}

Three of the participants had moved from overseas to take up positions as dean in Australia during the 1990s, 2000s and 2010s. They had mixed experiences with DCP3 and DCP4 having held educational leadership positions before migrating. DCP2 had moved from a clinical chair position to his deanship:
After ten years I was burnt out ... \{from the clinical position] ... keeping the university up, keeping the practice up ... I decided it was time to become some sort of head of department or dean ...I had a few false starts trying different jobs and then someone said there are some jobs in Australia and I came here (DCP2).

\section{Health Pathway}

In the late 2000 s and 2010 s a different trend emerged with the appointment of two deans from senior management positions in the health sector. Neither of these appointees had previous teaching experience or a background in the education sector:

I have had 15 years in senior leadership roles; it's been management leadership and clinical leadership, but certainly no strong education background. Probably this has been the harder part of this job...running a school is no big drama. If you can run a hospital you can run a school (HDP25).

Table 1. Education if deans during their work careers

\begin{tabular}{|c|c|c|c|c|c|c|c|}
\hline Degree completed & $\begin{array}{c}\text { Clinical } \\
\text { work }\end{array}$ & $\begin{array}{l}\text { Nurse educator - } \\
\text { hospital }\end{array}$ & $\begin{array}{l}\text { Lecturer- } \\
\text { university }\end{array}$ & $\begin{array}{l}\text { Leadership education- } \\
\text { university }\end{array}$ & $\begin{array}{c}\text { Hospital } \\
\text { management }\end{array}$ & $\begin{array}{l}\text { Senior health } \\
\text { management }\end{array}$ & Full-time study \\
\hline Bachelor Nursing & 4 & & & & 1 & & 1 \\
\hline $\begin{array}{l}\text { Bachelor other } \\
\text { discipline }\end{array}$ & 4 & 2 & & & & & \\
\hline $\begin{array}{l}\text { Certificate nursing } \\
\text { specialty (mental } \\
\text { health, midwifery, } \\
\text { acute care etc.) }\end{array}$ & 11 & & & & & & \\
\hline $\begin{array}{l}\text { General nursing } \\
\text { certificate }\end{array}$ & 3 & & & & & & \\
\hline $\begin{array}{c}\text { Associate } \\
\text { diploma/ Diploma } \\
\text { nurse education }\end{array}$ & 1 & 2 & & & & & \\
\hline $\begin{array}{c}\text { Graduate diploma } \\
\text { (other discipline) }\end{array}$ & 1 & 1 & & & & & \\
\hline $\begin{array}{c}\text { Masters } \\
\text { ( nursing, nursing } \\
\text { management, } \\
\text { nursing education) }\end{array}$ & 4 & 5 & 4 & 1 & & 2 & 4 \\
\hline $\begin{array}{l}\text { Masters (other } \\
\text { discipline }\end{array}$ & 1 & 1 & & & 1 & & 1 \\
\hline $\mathrm{PhD}$ & & & 13 & 10 & & 2 & 2 \\
\hline
\end{tabular}

Table: Pattern of education pathways of the deans indicating stage in career when academic degrees completed after initial nursing qualification. 
Table 2. Pathways to Deanship

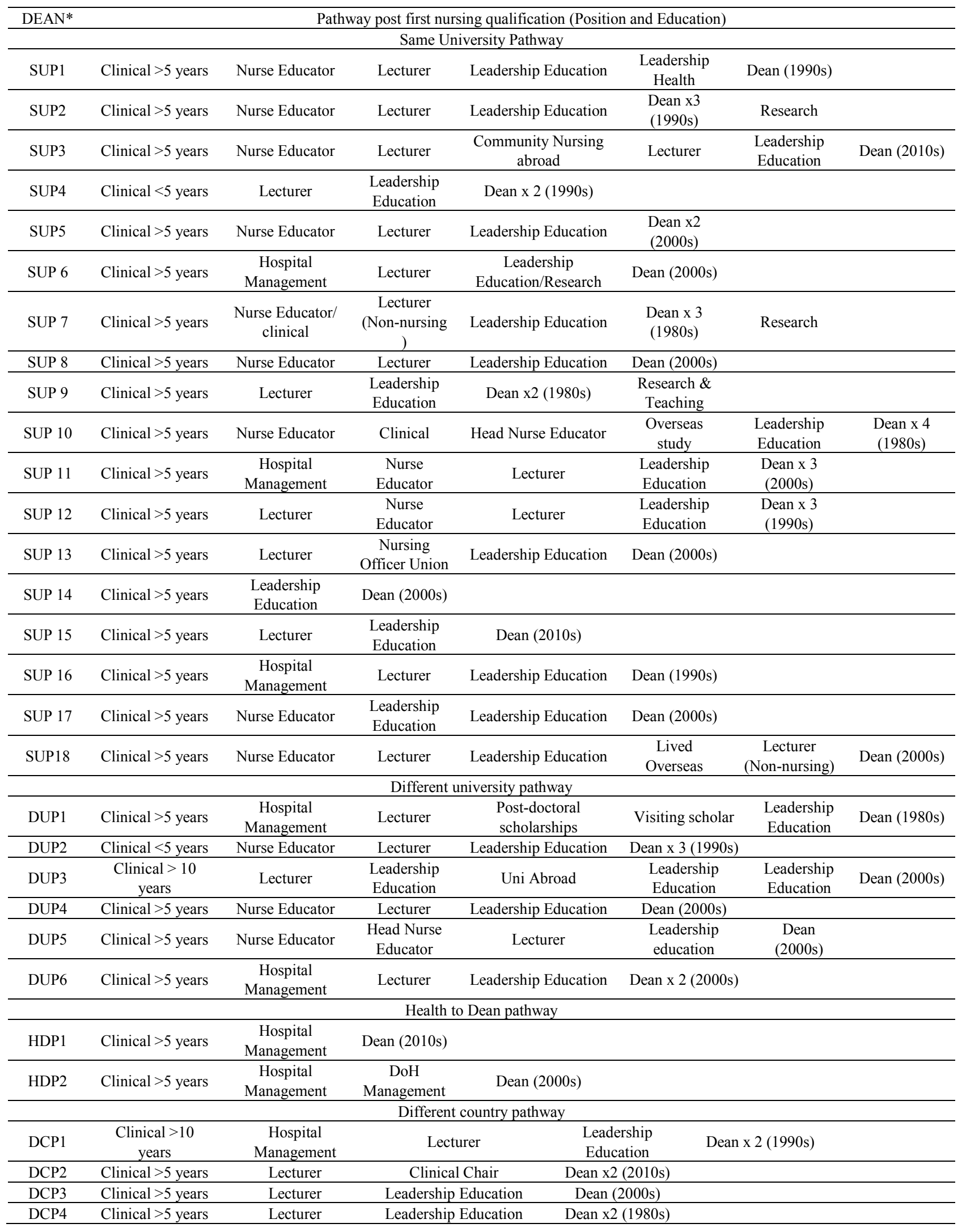

*Dean () indicates decade of first appointment as a Dean. 


\section{Discussion}

Most of the deans had a long atypical educational road to achieve their academic leadership potential. This is similar to other professional practice disciplines such as education, physiotherapy, occupational therapy, which moved into academia later than the more traditional disciplines such as law and medicine.[18-20] From the perspective of mentoring a new generation of future deans, time must be given for these nurses to gain their post graduate education through full-time study

Despite the different decades of first appointment which spanned some 40 years, there were similar patterns in the participants' journeys to deanship. Similar to other studies on deans in other disciplines, a common pathway was via promotion through a university to the deanship. Unlike many studies in the past, only a few had worked as associate deans or heads of department in nursing. As suggested by Green and Ridenour [6] they most commonly follow the professional pathway described by Morris [11].Therefore, as suggested by Wolverton et. al. [8] and Wolverton and Gonzales [22], universities tend to promote senior faculty to the deanship or is it as these authors suggest, being in the right place at the right time. However, as seen in the appointments to deanship of managers from health services in the late 2000s and 2010s, this pattern may be changing in response to the emphasis on financial and resource management now embedded in universities. In examining the educational pathways of the sample of deans in this study, only three had formal education in management and of the others HDP1, who came from a health service position to the deanship, had not pursued management qualifications. It has been suggested in the literature these nursing deans, like deans in other disciplines, learn through their experience in administrative positions either in the university or in other organisations. [4, 22, 23] To enhance this education, many universities are now formalising leadership and management programs for senior staff. [12, 23, 24]

\section{Implications}

Findings from this study highlight the often unplanned nature of the journey to deanship. This may reflect a time in history when nursing was at the threshold of establishing itself in universities in Canada, United Kingdom and Australia. However, with the predicted workforce crisis in academic nursing, there is a need to ensure that the trajectory to deanship is made clearer. There is also a need for formal education, and to identify prospective candidates as early as possible in their academic careers, so as to provide opportunities in administration and for formal leadership education. Formal mentoring is suggested by a number of authors, particularly for women deans. [12, 23, 25]

\section{Limitations}

In this qualitative study there was no examination of whether the pathway had made a better or more successful dean of nursing. Future research could pursue this. Another limitation is that the participants' ideas of what had influenced their career choices, in most instances were not recorded. It would be illuminative to follow up the seminal work of Redman [27] who examined the life and career relationships and experiences that influenced the assumption of the dean role. Future research could aim to explore how deans have melded their education and management experience in developing a career pathway to deanship. Another research interest could be whether there is any relationshjip between gender roles and attaining deanship.

\section{Conclusions}

There are multiple pathways to nursing deanship. No single pathway is the best. Most are journeys of discovery, opportunity and circumstance. Nevertheless, to prepare for future academic nursing leadership, these journeys need to planned, sign-posted and appropriately fuelled. Most journeys culminate in a destination. If we are to answer the never-ending question of "are we there yet"? Academic leadership requires further deliberation and a clearer articulation of the aspects of the role.

\section{Acknowledgements}

We are grateful to Anna McManus and Harrison Ng Chok for their support in publishing this document.

\section{REFERENCES}

[1] C. A. Isaac, L. S. Behar - Horenstein, and M. Koro Ljungberg, Women deans: leadership becoming. International Journal of Leadership in Education, 2009. Vol (2): p. 135-153.

[2] M. Bergin, NVivo 8 and consistency in data analysis: Reflecting on the use of a qualitative data analysis program. Nurse researcher, 2011. Vol (3): p. 6.

[3] L. Adams, Nursing academic administration: Who will take on the challenge? Journal of Professional Nursing, 2007. Vol (5): p. 309-315.

[4] J. F. Williams Ii, Leadership evaluation and assessment. Journal of Library Administration, 2001. Vol (3-4): p. 153-176.

[5] C. Jackson, et al., A review of nurse educator career pathways; a European perspective. Journal of Research in Nursing, 2009. Vol (2): p. 111. 
[6] A. Green and N. Ridenour, Shaping a career trajectory in academic administration: Leadership development for the deanship. Journal of Nursing Education, 2004. Vol (11): p. 489-495.

[7] P. Layne, Perspectives on Leadership from Female Engineering Deans. Leadership and Management in Engineering, 2010. Vol (4): p. 185-190.

[8] M. Wolverton, et al., The Changing Nature of the Academic Deanship. ASHE-ERIC Higher Education Report, Volume 28, Number 1. Jossey-Bass Higher and Adult Education Series. 2001: ERIC.

[9] S. Gevedon, Leadership behaviors of deans of top-ranked schools of nursing. The Journal of nursing education, 1992. Vol (5): p. 221.

[10] K. Miller-Rosser, et al., Analysing oral history: A new approach when linking method to methodology. International Journal of Nursing Practice, 2009. Vol(5): p. $475-480$.

[11] V. C. Morris, Deaning, middle management in academe. 1981: University of Illinois Press.

[12] D. F. Bright and M. P. Richards, The Academic Deanship: Individual Careers and Institutional Roles. The Jossey-Bass Higher and Adult Education Series. 2001: ERIC.

[13] M. J. Amery and K. E. Vanderlinden, Career paths for community college leaders. AACC/Leadership Series, 2002. Vol (3): p. 1-16.

[14] F. Mcdermid, et al., Factors contributing to the shortage of nurse faculty: a review of the literature. Nurse Educ Today, 2012. Vol (5): p. 565-9.

[15] L. Wilkes, et al., A repertoire of leadership attributes: an international study of deans of nursing. Journal of Nursing Management, 2013. Vol: p. n/a-n/a.

[16] P. Thompson, Voice of the Past: Oral History: Oral History. 2000: OUP Oxford.

[17] S. Kirby, A historical perspective on the contrasting experiences of nurses as research subjects and research activists. International Journal of Nursing Practice, $2004 \mathrm{Vol}$ (6): p. 272-279.

[18] S. Kirby, A historical perspective on the contrasting experiences of nurses as research subjects and research activists. International Journal of Nursing Practice, 2004. Vol(6): p. 272-279.

[19] R. Bamberg and E. Layman, Approaches to leadership development used by deans of allied health. Journal of Allied Health, 2004. Vol (2): p. 113-124.

[20] M. Del Favero, Disciplinary variation in preparation for the academic dean role. Higher Education Research \& Development, 2006. Vol (3): p. 277-292.

[21] C. A. Isaac, L. S. Behar-Horenstein, and M. Koro-Ljungberg, Women deans: Leadership becoming. International Journal of Leadership in Education, 2009. Vol (2): p. 135-153.

[22] M. Wolverton and M. J. Gonzales, Career Paths of Academic Deans. 2000. Vol.

[23] J. M. Montez, M. Wolverton, and W. H. Gmelch, The roles and challenges of deans. The Review of Higher Education, 2003. Vol (2): p. 241-266.

[24] M. B. Greicar, The professional preparation of academic deans, 2009, Bowling Green State University.

[25] R. L. G. Mitchell and P. L. Eddy, In the middle: Career pathways of midlevel community college leaders. Community College Journal of Research and Practice, 2008. Vol (10): p. 793-811.

[26] P. Layne. Women engineering deans in the United States: A new model for academic leadership. in ICWES 15: The 15th International Conference for Women Engineers and Scientists. 2011. Engineers Australia.

[27] G. M. Redmond, Life and career pathways of deans in nursing programs. Journal of Professional Nursing, 1991. Vol (4): p. 228-238.

[28] B. K. Redman, The dean of nursing as arbiter, antagonist, and advocate. Nursing Administration Quarterly, 2001. Vol (4): p. 57-63. 